\title{
As dissonâncias cotidianas nas rotinas dos jornais: o babitus jornalístico e a atribuição de um sentido hegemônico às notícias
}

\author{
Marcos Paulo da Silva \\ Universidade Federal de Mato Grosso do Sul (UFMS) - E-mail: marcos.paulo@ufms.br \\ Doutor em Comunicação Social pela Universidade Metodista de São Paulo (UMESP), \\ com estágio de doutorado-sanduíche na Syracuse University (NY, Estados Unidos).
}

\begin{abstract}
Resumo
A proposta do artigo é revisitar o debate teórico a respeito das dinâmicas de seleção e de construção das notícias a partir de um quadro de referência próprio da sociologia dos campos de Pierre Bourdieu. Parte-se de uma abordagem introdutória sobre a relevância das rotinas profissionais no processo construtivo do conteúdo noticioso. Na sequência, o conceito bourdieusiano de habitus é inserido como chave-explicativa para a relação entre a práxis jornalística e a atribuição de um sentido hegemônico às notícias. Os parâmetros de noticiabilidade são interpretados como representações simbólicas incorporadas ao habitus profissional dos jornalistas com base na identificação e na categorização sob o rótulo de notícia daqueles eventos que são dissonantes da regularidade cotidiana.
\end{abstract}

\section{Palavras-chave}

Jornalismo; noticiabilidade; habitus jornalístico.

\begin{abstract}
This article intends to revisit the theoretical debate about the dynamics of news selection and news construction based on a reference board related to the sociology of fields by Pierre Bourdieu. The discussion starts from an introductory approach about the relevance of the professional routines in the constructive process of news content. Afterward, the Bourdieu's concept of habitus is inserted as an explicative-key for the relation between the journalistic praxis and the attribution of a hegemonic sense to the news. The newsworthiness parameters are interpreted as symbolic representations incorporated to the journalistic professional habitus based on the identification and categorization as news of those events which are dissonant from the everyday regularity.
\end{abstract}

\section{Keywords}

Journalism; newsworthiness; journalistic habitus. 


\title{
Para situar o debate
}

\author{
"Case-se com um coveiro, com um distribuidor de cartas, \\ com um batedor de carteiras, mas nunca com um jornalista" \\ (Walter Burns, personagem do filme The Front Page, de Billy Wilder)
}

A frase que serve de epígrafe para este artigo pertence a Walter Burns, caricatural editor vivido por Walter Matthau na comédia The Front Page, de 1974, adaptada do teatro para o cinema pelo diretor norte-americano Billy Wilder. Burns, chefe-mor do diário Chicago Examiner, se dirige na ocasião a Peggy Grant, personagem de Susan Sarandon, uma comportada cantora e pretensa futura esposa do não menos caricatural Hildy Johnson, badalado repórter estrelado por Jack Lemmon. A trama se passa nos anos 1920 - véspera da grande depressão na economia dos Estados Unidos e tem como fio condutor o envolvimento de ambos - Johnson e Burns - em uma cômica cobertura jornalística sobre a condenação de um réu ao enforcamento.

Do ponto de vista da problematização da prática noticiosa contemporânea, um dos pontos de destaque desse longa-metragem de Billy Wilder produzido duas décadas depois de seu clássico A montanha dos Sete Abutres (Ace in the hole, de 1951) consiste, uma vez mais, na carnavalização que promove das rotinas jornalísticas a partir da exibição anedótica dos trejeitos profissionais historicamente difundidos no ambiente dos chamados "homens das notícias" - ou simplesmente newspapermen na tradição norteamericana. Tais trejeitos são ilustrados no filme pelos diversos elementos simbólicos capazes de aglutinar os jornalistas entre si e os separar das demais categorias profissionais - em especial daquelas categorias "relegadas" aos chamados "cidadãos comuns" - e particularmente pela odisseia do jovem repórter recém-formado (interpretado por Jon Korkes) que ainda não aprendeu os meandros da profíssão e tenta seguir os comportamentos dos colegas mais experientes.

O cômico exemplo de The Front Page é significativo no contexto do debate aqui pretendido por ser sintomático de um aspecto mais abrangente que perpassa as 
dinâmicas de seleção e de construção do conteúdo noticioso: o fato de os jornalistas compartilharem elementos simbólicos que resultam na identificação e na posterior caracterização sob o rótulo de "notícia" daqueles eventos cotidianos que são dissonantes de uma ordem simbólica - em geral hegemônica - socialmente disseminada. Esses elementos fazem dos jornalistas uma classe profissional detentora de um capital cultural peculiar que culmina - particularmente pelo manejo e pela reprodução de símbolos com significação no cotidiano - numa espécie de empoderamento simbólico também sobressaltado na sociedade (BOURDIEU, 1977; 2009). Todo esse conjunto de traços simbólicos compartilhado profissionalmente, ademais, concede à classe dos jornalistas - não raramente de modo caricatural, a exemplo dos boêmios personagens de Billy Wilder - uma proeminência social que muitas vezes não condiz com as condições de trabalho e com própria realidade econômica de seus integrantes ("nunca se case com um jornalista", alertara Walter Burns à noiva de Hildy Johnson sobre o ritmo de vida do amado). Ainda assim, jornalistas profissionais são correntemente acusados por críticos de mídia de reproduzirem em sua prática cotidiana - de forma impune e insolente, na perspectiva dos críticos mais inflamados - o mero sensacionalismo ou os interesses mais ávidos das elites políticas e econômicas.

A título dessa linha de raciocínio, pergunta-se: existe nas newsrooms uma espécie de "sala de justiça" em que jornalistas e representantes dos mais altos escalões da sociedade possam conspirar a respeito dos temas cotidianos e trocar informações sobre como interpretar cada acontecimento noticioso a partir de um vértice dominante ou com base no apetite explícito de uma manipulação sensacionalista da realidade? Certamente, pelo menos em sua natureza crua, essa hipótese pode ser descartada. De que modo, então, todo o arcabouço cultural que faz dos processos de seleção e de construção das notícias uma ampla inscrição simbólica atrelada aos sentidos dissonantes da sociedade - ou seja, aos acontecimentos simbolicamente dotados de noticiabilidade ganha, de fato, a dimensão prática das salas de redação? E mais: de que maneira, por sua vez, a ideia de uma racionalidade substancialmente instrumental - esta sim uma marca hegemônica característica da sociabilidade moderna - projeta-se nessa mesma 
prática noticiosa e permite a ela a disseminação de um sentido conservador de diluição das "dissonâncias" cotidianas - o sentido "explicativo" das notícias - e de manutenção de uma ordem simbólica estabelecida?

Esses questionamentos, apontamentos centrais do artigo, estão relacionados a processos simbólicos multifacetados e tomados como essenciais para a compreensão da atividade jornalística. A resposta a eles, por seu turno, foge de determinismos e recai sobre uma chave-explicativa fundamental para o entendimento da própria questão da noticiabilidade: o conceito bourdieusiano de habitus jornalístico. Antes de uma imersão mais profunda na aplicabilidade das reflexões de Pierre Bourdieu ao campo do jornalismo, entretanto, um delineamento da complexidade que envolve as rotinas balizadoras da prática noticiosa se faz necessário.

\section{As rotinas jornalísticas}

Os estudos sobre as chamadas "rotinas jornalísticas" não são recentes e remetem - ao menos no contexto das abordagens sociológicas modernas - às pesquisas norteamericanas na passagem da primeira para a segunda metade do século XX. Um desses estudos pioneiros consiste na análise funcionalista conduzida nos anos 1950 por Warren Breed (1960) sobre o "controle social" estabelecido nas redações jornalísticas nos Estados Unidos. A importância da abordagem de Breed, da mesma forma como anos antes havia feito o também pioneiro estudo de David White (1950) sobre o processo de gatekeeping, localiza-se na ênfase que projeta sobre uma etapa específica da dinâmica do newsmaking. Ao passo que White (1950) foca especificamente as decisões individuais tomadas pelos atores sociais denominados de gatekeepers, Breed (1960) amplia o olhar sobre a abrangência do fenômeno e lança luz sobre a socialização de regras implícitas no ambiente profissional dos jornalistas.

É certo que a análise eminentemente funcionalista do sociólogo norte-americano - tal como ensinava os cânones do modelo científico hegemônico do período - avalia a 
prática noticiosa como uma espécie de sistema fechado e, dessa maneira, não se faz suficiente para contemplar a complexidade da questão. Por outro lado, o estudo traz à tona temas pertinentes que ajudam a pautar a pesquisa acadêmica sobre jornalismo nas décadas seguintes. Na prática, Breed (1960, p.180) parte de um questionamento central bastante claro que norteia tanto sua coleta de dados quanto a interpretação que concede a eles: de que forma as implícitas regras profissionais partilhadas no interior das salas de redação, a despeito de suas inúmeras contradições, são seguidas? O núcleo da resposta projetada pelo autor situa-se no reconhecimento de que os jornalistas aprendem depressa a reconhecer as expectativas sobre o próprio trabalho de modo a evitar eventuais punições e atingir mais naturalmente o prestígio profissional (BREED, 1960, p.182). São ainda apresentadas seis razões que caracterizam a aceitação dessas regras no ambiente de trabalho: 1) a autoridade profissional explícita e a possibilidade de sanções diretas; 2) possíveis sentimentos de gratidão, compromisso ou estima pelos superiores; 3) a própria aspiração de mobilidade profissional; 4) a ausência de fidelidade a grupos de pressão (sindicatos, por exemplo); 5) o prazer natural pelo trabalho (o sentimento de bem-estar atrelado à "solidariedade" profissional compartilhada com os demais jornalistas, ainda que estejam em funções superiores); e, finalmente, 6) a compreensão da ideia de "notícia" como uma espécie de "valor superior" a ser constantemente buscado (independentemente do local de trabalho, do horário ou da função exercida) (BREED, 1960, p.184-188).

Em que pese o pioneirismo da pesquisa de Warren Breed e o lugar de referência que isso lhe concede na história dos estudos comunicacionais nos Estados Unidos, novos olhares são naturalmente projetados sobre a temática das rotinas jornalísticas nas décadas que seguem. Outro nome norte-americano que recebe destaque, nesse sentido, é o da também socióloga Gaye Tuchman. Ao menos dois estudos que antecedem a principal obra da autora sobre mídia - nomeadamente, "Making news: a study in the construction of reality", de 1978 - são correntemente citados em pesquisas sobre a atividade jornalística pelo foco depositado nas rotinas profissionais: "Making news by doing work: routinizing the unexpected", datado de 1973, e "The exception proves the 
rule: the study of routine news practices", publicado em 1977. No primeiro caso, Tuchman (1973) recorre também à concepção de "controle" - tema predominante na sociologia do período -, mas, de modo distinto a Breed (1960), realça o fluxo propriamente dito da produção noticiosa. Em suma, a autora coloca em questão a maneira como a rotinização constitui um componente pragmático que facilita o controle dos fluxos de trabalho nas redações, reduzindo, por conseguinte, o amplo universo de eventos cotidianos em determinadas categorias que conformam as notícias. Tuchman (1973, p.116-117) enfatiza que as "tipificações" tomadas como prontas pelos jornalistas representam soluções práticas para problemas e tarefas incorporadas ao dia-a-dia das redações. Assim, o uso corrente de categorias que pautam a atividade de seleção e redação das notícias - a exemplo das denominadas "notícias quentes" e "notícias frias"1 - resulta em um controle implícito no trabalho de repórteres e editores. Mais tarde, a socióloga aponta que essa espécie de "rotinização do inesperado" acaba por determinar a própria concepção de noticiabilidade, reconhecendo, portanto, a influência sobre a produção jornalística do modo como os acontecimentos noticiáveis são racionalizados nas rotinas profissionais (TUCHMAN, 1977, p.45).

Outros autores, ainda no cenário norte-americano, também se distinguem pela ênfase nas dinâmicas simbólicas imbricadas na rotinização das práticas noticiosas. Em período contemporâneo ao de Gaye Tuchman, por exemplo, Leon Sigal (1973) enumera uma série de procedimentos operacionais partilhados pelos repórteres no relacionamnto com as fontes e na captação das notícias. Já Herbert Gans (2004) aborda a relação existente entre as pressões profissionais e as práticas de autocensura e de autorregulação disseminadas nas redações jornalísticas. Contudo, vem de Todd Gitlin, outro sociólogo de destaque no contexto dos Estados Unidos, uma das mais essenciais considerações ao fio condutor percorrido até aqui pela discussão. Em sua análise sobre o enquadramento recebido no país pelo movimento político da New Left nos anos 1960, Gitlin (2003) sugere que as engrenagens das rotinas jornalísticas são engraxadas por elementos típicos de hegemonia - e quando em pauta estão tais elementos, recorda Franco Moretti (2009,

1 Chamadas em inglês de "hard news" e "soft news", respectivamente. 
p.212), não há "pureza" requerida para além de "plasticidade" e da "camuflagem" cotidiana de componentes ideológicos.

É neste ponto que se revestem de pertinência as reflexões teóricas de Pierre Bourdieu. O sociólogo francês concede profundidade ao debate ao permitir uma aproximação entre o processo social de "rotinização das práticas" e a operacionalização do conceito gramsciano de hegemonia - relação outrora evidenciada por Jesús MartinBarbero (2003, p.123-124). Nessa conjuntura, a concepção de habitus jornalístico estabelece-se como uma chave-explicativa fundamental para a maneira como os eventos cotidianos "dissonantes" - isto é, os acontecimentos originários das quebras de expectativas instituídas pela regularidade do senso comum - são localizados como eventos noticiáveis no pragmatismo da atividade jornalística.

\section{O habitus bourdieusiano como chave-explicativa}

Enfim, o que realmente se coloca por trás do complexo conceito bourdieusiano de habitus jornalístico? Do ponto de vista epistemológico, a ideia de habitus situa-se como parte indispensável na tríade que sustenta a chamada "sociologia dos campos" de Bourdieu. Ao lado das noções de "campo" e de "capital", a concepção integra o quadro conceitual que, segundo a perspectiva do pensador francês, permite explicar as problemáticas intrínsecas do mundo social. A pertinência da conceituação, no entanto, não impede que recaia sobre ela uma série de críticas a respeito de sua simplicidade estrutural $^{2}$. Em resposta, Bourdieu identifica um cenário de "incompreensão" sobre o que precisamente suas noções pretendem explicar e afirma ser os sistemas simbólicos o foco de sua teoria (BOURDIEU, 2009, p.72). Para o autor, em combate a uma possível rotulação de reducionista, a noção de habitus exprime exatamente a recusa a toda uma série de alternativas nas quais as ciências sociais já haviam se encerrado: a da

2 O sociólogo chega a apresentar o conceito de campo como um "espaço estruturado de posições" e o habitus, consequentemente, como a objetivação do exterior estruturado nas atitudes subjetivas dos sujeitos, posição que o aproxima da perspectiva estruturalista (BOURDIEU, 1983, p. 89). 
consciência, a do inconsciente, a do finalismo e a do mecanicismo (BOURDIEU, 2009, p. 60). Dessa forma, o conceito é entendido pelo sociólogo como "um conhecimento adquirido e também um haver, um capital (de um sujeito transcendental na tradição idealista); (...) uma disposição incorporada, quase postural” (BOURDIEU, 2009, p. 61) - ou, como resume em "A economia das trocas simbólicas", trata-se simplesmente de disposições inconscientes que estão presentes em diferentes sujeitos, levando-se em conta que tais disposições são resultado da "interiorização de complexas estruturas objetivas presentes numa sociedade" (BOURDIEU, 1974, p. 201).

No interior de sua complexidade, o conceito de habitus também se articula diretamente com a concepção de "campo" cunhada pelo próprio Bourdieu. Um campo, nesse sentido, representa um "ponto de vista" a partir do qual se pode captar "posições produtoras de visões, obras e tomadas de posição, a que correspondem classes de agentes providos de propriedades distintivas, portadores de um habitus, também socialmente construído" (MICELI, 2003, p. 65). Por conseguinte, o habitus constitui um dos elementos centrais que permite a operacionalização dos sistemas simbólicos no interior dos campos sociais - a exemplo do campo jornalístico. O habitus ainda recupera duas características da noção aristotélica de "hábito"; isto é, além de ser "socialmente construído", remete a um saber incorporado que dispensa "a ação calculadora da consciência" (BARROS FILHO e MARTINO, 2003).

Especificamente sobre a atividade noticiosa - foco da corrente discussão, Bourdieu reserva um espaço significativo em sua vasta produção reflexiva para traçar considerações a respeito do funcionamento dos meios de comunicação. Reassume, assim, a postura acadêmica de reaplicar sua conceituação da teoria geral dos campos em novos objetos - tornando-os "tão inventivos quanto suas aplicações conceituais originais" (BOURDIEU, 2009a, p. 63). Tais reflexões, portanto, devem ser compreendidas no contexto mais amplo de sua atividade intelectual. Em seu estudo sobre a televisão, realizado já na década de 1990, por exemplo, Bourdieu (1997) retoma o conceito de campo para delinear algumas das particularidades que marcam a prática jornalística. Define o autor: 
Um campo é um espaço social estruturado, um campo de forças - há dominantes e dominados, há relações constantes, permanentes, de desigualdade, que se exercem no interior desse espaço - que é também um campo de lutas para transformar ou conservar esse campo de forças. Cada um, no interior desse universo, empenha em sua concorrência com os outros a força (relativa) que detém e que define sua posição no campo e, em consequência, suas estratégias. (BOURDIEU, 1997, p. 58).

O campo jornalístico, nessa perspectiva, é encarado como um espaço em constante tensionamento - "um microcosmo que tem leis próprias e que é definido por sua posição no mundo global e pelas atrações e repulsões que sofre da parte dos outros microcosmos" (BOURDIEU, 1997, p. 55). A partir do vértice teórico do sociólogo francês, o entendimento do campo jornalístico como autônomo consiste necessariamente no reconhecimento de que sua compreensão não pode ser pensada de maneira direta como resultante de fatores externos. Tal posição é conflitiva, logo em primeira instância, com os modelos explicativos de caráter determinista, como os de cunho político ou econômico, por exemplo - este último associado a determinadas interpretações da tradição ortodoxa do marxismo que, nas palavras do próprio Bourdieu (1997, p. 56), “denuncia sem esclarecer nada". Em contrapartida, aponta o autor, a atividade jornalística requer uma compreensão própria a partir do entendimento específico de suas tensões:

A concorrência econômica entre as emissoras ou os jornais pelos leitores e pelos ouvintes ou, como se diz, pelas fatias de mercado realiza-se concretamente sob a forma de uma concorrência entre os jornalistas, concorrência que tem seus desafios próprios, específicos, o furo, a informação exclusiva, a reputação na profissão, etc, e que não se vive nem se pensa como uma luta puramente econômica por ganhos financeiros, enquanto permanece sujeita às restrições ligadas à posição do órgão de imprensa considerado nas relações de força econômicas e simbólicas. (BOURDIEU, 1997, p. 57-58).

Assume-se, nesse panorama, que as particularidades do campo jornalístico apresentadas por Bourdieu (1997) fazem-se essenciais em diferentes aspectos para o 
entendimento dos processos de seleção e de construção das notícias. Um primeiro aspecto consiste no próprio modo de operacionalização da atividade noticiosa no interior do campo do jornalismo. O sociólogo chama atenção, nesse sentido, para o fato de a estrutura dos meios de comunicação estabelecer-se socialmente em consonância com a ideia de uma "ordem simbólica consensualmente estabelecida" - ou, nos termos aristotélicos, em torno da concepção de doxa. Tal operação pode ser observada em paralelo com as reflexões de Roland Barthes (1988), que observa o discurso do jornalismo convencional como um modelo de discurso "encrático" (ou seja, inscrito socialmente em consonância com um padrão doxal de interpretação da realidade), ou com as reflexões de Muniz Sodré (2009) sobre relação entre jornalismo e senso comum. Para o autor brasileiro, embora o senso comum estabeleça-se no campo do sensível (em oposição ao conhecimento sistemático, à episteme), a atividade jornalística atua de modo a não desprezar o conhecimento doxal, aspecto que se faz necessário na construção de um sentido de "pertencimento à comunidade".

Além disso, especificamente sobre a questão da noticiabilidade, Pierre Bourdieu (1997, p.25) recorre a uma metáfora: a dos óculos. Os óculos - que podem ser compreendidos como uma articulação simbólica no interior do habitus, espécie de "social incorporado" - são utilizados pelo teórico para explicar as seleções realizadas pelos jornalistas em função de categorias que lhes são próprias. Nos termos do autor, “os jornalistas têm 'óculos' especiais a partir dos quais veem certas coisas e não outras; e veem de certa maneira as coisas que veem. Eles operam uma seleção e uma construção do que é selecionado" (BOURDIEU, 1997, p. 25). Esse processo, no entanto, não escapa a uma importante contradição: a homogeneização da informação que contraditoriamente é resultante do processo de concorrência em busca do "furo" jornalístico. Nas palavras de Bourdieu:

O extra-ordinário é também e sobretudo o que não é ordinário com relação aos outros jornais. É o que é diferente do ordinário e o que é diferente do que os outros jornais dizem do ordinário, ou dizem ordinariamente. É uma limitação terrível: a que impõe a perseguição do furo. Para ser o primeiro a ver e a fazer alguma coisa, está-se 
disposto a quase tudo, e como se copia mutuamente visando a deixar os outros para trás, fazer antes dos outros, acaba-se por fazerem todos a mesma coisa. (BOURDIEU, 1997, p. 26-27).

No campo jornalístico, portanto, a busca da exclusividade, que em outros campos profissionais pode produzir a originalidade, acaba por resultar - segundo a visão de Bourdieu (1997) - na uniformização; dinâmica anedoticamente mostrada no filme de Billy Wilder a partir da rotina de apuração das notícias no interior da sala de imprensa de uma delegacia de polícia (apuração, esta, realizada por apenas um repórter enquanto os demais jogam cartas). Na prática profissional, jornalistas convivem coletivamente, andam em grupos e partilham experiências e narrativas. Trata-se, como na metáfora de Nelson Traquina (2008), de uma espécie de "matilha" que caminha para a homogeneização enquanto persegue a notícia em "primeira mão".

No mais, interpretado como um "microcosmo autônomo", o conceito de campo jornalístico pode também ser compreendido a partir de seus "mecanismos de autopreservação"; ou seja, a partir dos mecanismos socialmente incorporados que se reúnem em torno de dois aspectos centrais: a contundente autocrítica do campo e a defesa incessante das críticas externas (BARROS FILHO E SÁ MARTINO, 2003, p.112-113). Assim, ao passo em que o discurso de autocrítica possibilita, no plano simbólico, uma impressão de independência e autonomia (afastando do debate algumas contradições que condicionam sua real prática), a defesa das críticas externas, por outro lado, corporifica um discurso de autolegitimação sustentado na suposta defesa do "interesse público". Por sua vez, as práticas profissionais propriamente ditas, a exemplo dos "mecanismos de autopreservação" do campo, também podem ser observadas a partir de critérios nem sempre estabelecidos de formas objetivas e mensuráveis. Dessa maneira, apresentam-se como consequências de ações anteriores (representações simbólicas incorporadas) e com efeitos objetivados (orientados em seus sentidos práticos) - como ilustra a luta por aceitação entre os pares do jovem e inseguro repórter vivido por Jon Korkes em The Front Page. O habitus profissional é, então, entendido como uma espécie de "princípio gerador e regulador das práticas cotidianas" dos jornalistas 
(BARROS FILHO e MARTINO, 2003, p.115).

Em perspectiva semelhante, Robert Darnton (1990) destaca a necessidade de compreensão da prática noticiosa no interior de um conjunto próprio de relações simbólicas incorporadas às rotinas profissionais das redações. Nesse sentido, o historiador norte-americano situa o jornalismo no limiar de um sistema de valores previamente compartilhado a partir de padrões culturais vigentes. Em outros termos, consiste no reconhecimento de que a produção jornalística busca sempre respaldo em concepções culturais prévias que influenciam e são influenciadas (num jogo dinâmico) pela atividade de seleção noticiosa. Conforme as reflexões de Darnton (1990, p.87), o jornalismo possui uma espécie de "mitologia própria" culturalmente incorporada à sua rotina produtiva, sendo que os jornalistas "aprendem depressa a ler o sistema de status e não têm dificuldades em escolher modelos de identidade positivos e negativos". Ainda além, assimilam com precisão princípios como "imperturbabilidade, precisão, velocidade, esperteza, firmeza, pragmatismo e energia” (DARNTON, 1990, p.89).

Embora não se refira nominalmente a Pierre Bourdieu, Darnton supõe uma modalidade própria de incorporação do capital simbólico compartilhada no interior do campo jornalístico. Desse modo, o "furo" e o deadline, entre outros componentes da cultura profissional, são vistos como pontos fulcrais de nivelamento no mercado das trocas simbólicas do campo. Essa reflexão permite também que os critérios de noticiabilidade sejam entendidos muito mais como representações simbólicas incorporadas ao habitus profissional do jornalismo do que como elementos objetivos supostamente retirados da realidade (os chamados "valores-notícia"). O conteúdo de um dado veículo, por consequência, longe de ser enquadrado deterministicamente nas imposições econômicas ou nas limitações técnicas de seu suporte (como pregam algumas das mais representativas correntes teóricas da comunicação), deve - de fato “caber em concepções culturais prévias relacionadas com a notícia” (DARNTON, 1990, p.96).

Tal olhar para a noticiabilidade com base nos conceitos de habitus e de campo de Bourdieu permite, finalmente, uma ampliação de perspectiva frente à compreensão da 
questão a partir de seus processos técnico-operacionais - sejam aqueles vinculados às “categorias desviantes" ou, nos termos de Shoemaker (1996), às dimensões teóricas da "significância social". Pelo ponto de vista aqui adotado, todas essas categorias de seleção das notícias (ou "óculos", para fazer uso da metáfora de Bourdieu) devem ser compreendidas no contexto próprio dos tensionamentos do campo jornalístico e em seu diálogo com a operacionalização de processos sociais hegemônicos. Como microcosmo autônomo, portanto, o campo jornalístico requer reflexões próprias no entendimento de suas dinâmicas.

\section{Algumas considerações finais}

O processo de inscrição cultural dos elementos dissonantes da regularidade cotidiana na práxis jornalística (ou seja, daqueles elementos considerados "noticiáveis"), longe de constituir um mero decalque, é dotado de complexidade e passa pela operacionalização no plano empírico de diferentes componentes simbólicos compartilhados socialmente. É neste ponto que, como ressaltado acima, se reveste de propósito a aplicação da concepção bourdieusiana de habitus. O conceito proposto pelo sociólogo francês representa, assim, uma importante ferramenta para explicar o modo como os padrões culturais intrínsecos na sociedade - entenda-se aqui, sobretudo, os sentidos de "operacionalização da existência" e de "domesticação do acaso" (BIRMAN, 2010; LUCKÁCS, 2010) oriundos de um padrão hegemônico de racionalidade instrumental - são transcodificados e disseminados na prática noticiosa. Isto é, tal como abstraído das reflexões de Robert Darnton (1990), reconhece-se a existência dos critérios de noticiabilidade como um tipo peculiar de representação simbólica incorporada ao habitus do campo jornalístico; um modo particular de "social incorporado", ou, nas palavras do próprio Bourdieu (1974, p.201), de "interiorização de complexas estruturas objetivas presentes numa sociedade".

Nesse cenário, ao menos quatro questões teóricas já mencionadas no decorrer do artigo merecem ser recuperadas: 1) a disseminação social da atividade noticiosa em 
consonância com a ideia aristotélica de "senso comum" - ou doxa; 2) a relação entre tal “ordem simbólica comumente consensual” - intrínseca e extrínseca ao campo - e os processos simbólicos - aparentemente contraditórios - de uniformização do conteúdo noticioso; 3) os mecanismos de autolegitimação e autopreservação do jornalismo que viabilizam tais operações; e, por último, 4) a disseminação social desses mecanismos a partir de representações simbólicas incorporadas ao habitus do campo jornalístico. Admite-se, assim, sobretudo em termos de problematização, que tais pontilhamentos teóricos apresentam-se como chaves-explicativas alternativas e viáveis para $o$ entendimento dos processos de seleção noticiosa quando comparados ao enquadramento automático do conteúdo noticioso em categorias delimitáveis de critérios de noticiabilidade (a raridade, a proximidade, o ineditismo, o impacto, o conflito, o escândalo, a catástrofe, entre tantos outros $)^{3}$. Dessa maneira, a despeito de eventuais classificações que possam ser operacionalmente aplicáveis para tais critérios noticiosos - das elaborações clássicas aos aprimoramentos mais contemporâneos de caráter sociológico -, reconhece-se que as reflexões cunhadas por Pierre Bourdieu podem proporcionar um arcabouço teórico melhor acabado para o entendimento da complexidade simbólica por trás dos processos de seleção das notícias (o que deposita ainda mais comicidade sobre as caricaturas exibidas por Billy Wilder nos personagensjornalistas de The Front Page).

Da mesma forma, as elaborações conceituais propostas pelo sociólogo francês abrem frutíferas possibilidades de diálogo com outras formulações teóricas no entendimento da atividade jornalística. A noção de habitus, nesse sentido, ao realizar a função de estrutura intermediária e proporcionar a mediação entre as "condições objetivas de funcionamento de uma sociedade" e as "aptidões subjetivas de seus membros", pode ser posta em interface com a proposta teórica de Patrick Charaudeau. Entre outros aspectos, o entendimento da noticiabilidade a partir das contribuições do linguista francês recai sobre a valorização da articulação entre os aspectos situacionais

3 Uma série de estudos significativos e reconhecidos no campo dos estudos teóricos do jornalismo pontuam essas categorias. Ver, por exemplo: Wolf (2003), Traquina (2008) e Shoemaker (1996). Para acesso a uma sistematização crítica de tais categorias de noticiabilidade, ver também: Silva (2005). 
(externos) e linguísticos (internos) que se mobilizam na conformação do discurso informativo - ao que parece encaixar-se o entendimento do habitus.

Mais especificamente, entende-se que a operacionalização no jornalismo das marcas culturais provenientes do plano macrossocial - ou seja, das instâncias socioculturais e econômicas repousadas no espaço discursivo do "externo-externo" segundo a metáfora da "máquina midiática" de Charaudeau (2003) - ocorre propriamente no local de pertinência do "externo-interno" - isto é, no espaço discursivo interpretado como instância "micro" da cadeia. Assim, a passagem do "plano situacional” ao "plano discursivo" (CHARAUDEAU, 2003) - ou, em outros termos, a projeção no plano pragmático de valores que são previamente compartilhados a partir de padrões culturais vigentes na sociedade - possui seu suporte operacional na complexidade do habitus. Enfim, como em poucas outras circunstâncias, o complexo conceito bourdieusiano encontra nesse peculiar contexto da atividade jornalística tão clara ressonância na definição atribuída a ele por Martin-Barbero (2003, p.123): “o produto da interiorização dos princípios de um expediente cultural capaz de perpetuar nas práticas os princípios de um expediente interiorizado".

\section{Referências Bibliográficas}

BARROS FILHO, Clóvis de, MARTINO, Luís Mauro Sá. O habitus na comunicação. São Paulo: Paulus, 2003.

BARTHES, Roland. O rumor da língua. São Paulo: Brasiliense, 1988.

BOURDIEU, Pierre. A economia das trocas simbólicas. São Paulo: Perspectiva, 1974.

BOURDIEU, Pierre. Outline of a theory of practice. Cambridge: Cambridge University Press, 1977.

BOURDIEU, Pierre. Questões de sociologia. Rio de Janeiro: Marco Zero, 1983.

BOURDIEU, Pierre. Sobre a televisão. Rio de Janeiro: Zahar, 1997.

BOURDIEU, Pierre. O poder simbólico. 12.ed. Rio de Janeiro: Bertrand do Brasil, 2009.

BREED, Warren. Social control in the news room: a functional analysis. In: SCHRAMM, Wilbur. Mass communications: a book of readings selected. Urbana, Chicago e Londres: University of Illinois Press, 1960. 
Estudos em Jornalismo e Mídia - Vol. $10 \mathrm{~N}^{\circ} \mathrm{I}$ - Janeiro a Junho de 2013

CHARAUDEAU, Patrick. EI discurso de la información: la construcción del espejo social. Barcelona: Gedisa Editorial, 2003.

DARNTON, Robert. O beijo de Lamourette: mídia, cultura e revolução. São Paulo: Companhia das letras, 1990.

GANS, Herbert J. Deciding what's news: a study of CBS Evening News, NBC Nightly News, Newsweek and Time. Edição ampliada comemorativa de 25o. aniversário. Evanston, Illinois: Northwestern University Press, 2004.

GITLIN, Todd. The whole world is watching: mass media in the making and unmaking of the New Left. Berkeley, Los Angeles e Londres: University of California Press, 2003.

MARTIN-BARBERO, Jesus. Dos meios às mediações. Rio de Janeiro: UFRJ, 2003.

LUKÁCS, György. Soul \& form. New York: Columbia University Press, 2010.

MICELI, Sérgio. Bourdieu e a renovação da sociologia contemporânea da cultura. In: Tempo Social. Revista de Sociologia da Universidade de São Paulo. FFLCH-USP. Vol. 15. N. 1, abril, 2003.

MORETTI, Franco. Romance: teoria e história. Revista Novos Estudos. Cebrap, n. 85. 2009.

RIBEIRO, Lavina Madeira. Comunicação e Sociedade: cultura, informação e espaço público. São Paulo: E-papers, 2004.

SHOEMAKER, Pamela. J. Hardwired for news: Using biological and cultural evolution to explain the surveillance function. Journal of Communication, 46, 1996.

SIGAL, Leon V. Reporters and officials: the organization and politics of newsmaking. Lexington, Toronto e Londres: D.C. Heath and Company, 1973.

SILVA, Gislene. Para pensar critérios de noticiabilidade. Revista Estudos em Jornalismo e Mídia. Universidade Federal de Santa Catarina. vol. 2, n. 1, 2005.

SODRÉ, Muniz. A narração do fato: notas para uma teoria do acontecimento. Petrópolis (RJ): Vozes, 2009.

TRAQUINA, Nelson. Teorias do jornalismo: a tribo jornalística / uma comunidade interpretativa internacional. 2.ed. Florianópolis: Insular, 2008.

TUCHMAN, Gaye. Making news by doing work: routinizing the unexpected. American Journal of Sociology, v.79, n.1, 1973.

TUCHMAN, Gaye. The exception proves the rule: the study of routine news practices. In: HIRSCH, Paul M., MILLER, Peter V., KLINE, Gerald (Orgs.). Strategies for communication research. Beverly Hills e Londres: Sage Publications, 1977.

WHITE, David Manning. The gatekeeper: a case study in the selection of news. Journalism Quarterly, n.27, 1950.

WOLF, Mauro. Teorias da comunicação. 8.ed. Lisboa: Editorial Presença, 2003.

Este artigo e todo o conteúdo da Estudos em Jornalismo e Mídia

estão disponíveis em http://www.periodicos.ufsc.br/index.php/jornalismo/index

\section{Estudos em Jornalismo e Mídia está sob a Licença Creative Commons}

